\title{
Jonson e Shakespeare: a noção de autoria no teatro inglês do início da Era Moderna
}

\author{
Amanda Fiorani Barreto ${ }^{\mathrm{i}}$
}

\section{RESUMO}

No início da Era Moderna inglesa, a colaboração foi a forma de produção textual dominante do teatro renascentista (MASTEN, 1997). O âmbito teatral desse período, portanto, apresenta um conceito bem diferente de autoria em comparação com o que temos atualmente (ORGEL, 1991). O presente artigo se propõe a discutir a noção de autoria dessa era, considerando de que forma Ben Jonson (1572-1637) e William Shakespeare (1564-1616) lidaram com essa questão durante as suas carreiras. Em meio a um contexto em que a colaboração era a prática predominante (WELLS, 2006; GIDDENS, 2010), ambos parecem ter encontrado formas diferentes, porém efetivas de afirmar a sua autoria. Dessa forma, este artigo busca discutir a noção de autoria do início da Era Moderna, levando em conta como esses autores, considerados por muitos os mais representativos do período, lidaram com essa questão.

Palavras-chave: Ben Jonson; Renascimento Inglês; William Shakespeare; Autoria.

\begin{abstract}
During the English early modern period, collaboration was the dominant form of textual production of the Renaissance theatre (MASTEN, 1997). The theatrical scene of the period, therefore, present quite a different conception of authorship than the one considered nowadays (ORGEL, 1991). This text aims at discussing the notion of authorship of the era, considering the ways in which Ben Jonson (1572-1637) and William Shakespeare (1564-1616) dealt with this matter in their careers. Within a context in which collaboration was the predominant practice (WELLS, 2006; GIDDENS, 2010), both authors seem to have found different, but effective ways of exerting their authorship. In this way, this article seeks to discuss the notion of authorship of the early modern period, reflecting on how these authors, considered by many the two most representative authors of the period, dealt with this matter.
\end{abstract}

Keywords: Ben Jonson; English Renaissance; William Shakespeare; Authorship.

\footnotetext{
${ }^{\mathrm{i}}$ Mestranda em Estudos da Linguagem pela Pontifícia Universidade Católica do Rio de Janeiro (PUC-Rio) e bolsista FAPERJ.

Email: af_barreto@hotmail.com
} 
Peças teatrais, de forma mais ampla, são colaborativas por natureza, e isso é especialmente verdade quando consideramos a produção teatral do início da Era Moderna inglesa. De fato, a colaboração foi a forma de produção teatral dominante das eras elisabetana e jacobina (MASTEN, 1997). Por consequência, a noção de autoria da época é bem diferente da vigente, que remonta à ideia romântica do autor como dono de seus textos. Ben Jonson (1572-1637) e William Shakespeare (1564-1616), considerados por muitos acadêmicos os dramaturgos mais representativos do período, oferecem um contraponto interessante para a cultura de colaboração daquele momento, exercendo controle sobre as suas obras de formas diferentes. O presente artigo irá discutir a noção de autoria do início da Era Moderna inglesa de forma geral e considerar como Jonson e Shakespeare lidaram com esse aspecto em suas carreiras.

Iremos traçar brevemente o momento do surgimento da necessidade da identificação do autor em relação a sua obra por meio da etimologia da palavra anônimo (anonymous), que ressalta a ausência desse autor. Em seguida, discutiremos a forma com que Ben Jonson exerce autoridade sobre as suas obras desde a sua primeira publicação. Shakespeare, por outro lado, não parece ter se preocupado com esse aspecto em relação a suas publicações, encontrando outra forma, mesmo que aparentemente não intencional, de conseguir exercer esse controle em meio à cultura de colaboração do âmbito teatral como um todo.

\section{TEATRO, COLABORAÇÃo E A NOÇÃo DE AUTORIA NO TEATRO DO RENASCIMENTO INGLÊS}

O teatro da modernidade nascente inglesa é um lócus para discussão acerca da noção de autoria. Foi durante o século XVI que o entendimento do texto enquanto propriedade começou a surgir (FEATHER, 1999). Nesse período, a colaboração foi a forma de produção textual dominante do teatro renascentista inglês, e as peças eram muitas vezes reconhecidas apenas pelo nome da companhia de teatro que as havia comprado, e não pelo nome de seu(s) autor(es). De fato, como evidenciado pelo levantamento de Gerald Eades Bentley, de todas as peças escritas por dramaturgos profissionais naquele momento, "ao menos metade [...] incorporou a escrita de mais de 
um homem"1 (BENTLEY, G.E., 1974, p. 199 apud MASTEN, 1992, p. 399). A ideia atual de que a autoridade sobre um texto é de seu autor, portanto, difere bastante do conceito de autoria presente no início da Era Moderna inglesa. Como afirmado por Stephen Orgel, a noção de que "a autoridade de um texto deriva do autor quase nunca é verdade" 2 (ORGEL, 1991 apud KASTAN, 1991). É importante, então, estabelecermos com mais detalhes como a questão de autoria se configurava nesse contexto teatral.

O teatro foi o espaço que possibilitou a escrita como profissão no Renascimento inglês, mas, ao mesmo tempo, era um local em que noções de autoria eram especialmente complexas de se definir. Os textos teatrais durante as eras elisabetana e jacobina, depois de adquiridos pelas companhias de teatro, não eram mais vistos como propriedade do dramaturgo, mas da companhia que os comprou. De fato, podemos dizer que as instâncias que controlavam e detinham autoridade sobre um texto eram, de forma geral, as companhias de teatro e a Stationer's Company ${ }^{3}$. Como afirmado por Jeffrey Masten, "peças colaborativas dispersam a voz autoral (ou melhor, a nossa noção historicamente

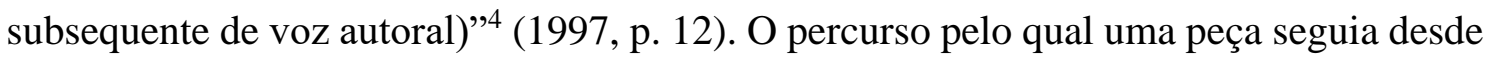
a sua concepção é muito bem explicado no seguinte trecho:

\footnotetext{
A criação de uma peça era um processo colaborativo, com o autor de forma alguma no centro da colaboração. A companhia encomendava a peça, geralmente estipulava o assunto, muitas vezes fornecia o enredo, muitas vezes dividido, cena por cena, para vários dramaturgos. $\mathrm{O}$ texto assim produzido era um modelo funcional, que a companhia então revisava conforme parecia apropriado. O autor tinha pouco ou nenhum poder de decisão sobre essas revisões: o texto pertencia à companhia, e a autoridade representada pelo texto - estou falando sobre o texto performático - é da companhia, os proprietários, não a do dramaturgo, o autor. ${ }^{5}$ (ORGEL, 1991, p. 83-84, grifo do autor).
}

Para ilustrar ainda mais a perda de controle que os dramaturgos tinham sobre as peças que vendiam, há evidências de que elas eram muitas vezes revisadas posteriormente, às vezes por outros dramaturgos que não o(s) autor(es), o que era em si uma forma de colaboração anacrônica. Um exemplo disso está documentado nos diários de Philip Henslowe - empresário do ramo teatral da época que manteve diários detalhados do funcionamento de seus teatros - quando ele registra que havia contratado Ben Jonson para fazer alterações em A Tragédia Espanhola de Thomas Kyd ${ }^{6}$, em 1602.

A questão da necessidade de identificar a autoria de um texto e a autoridade de escritores sobre suas obras pode ser remontada por meio da definição da própria palavra 
que nega esse pertencimento: anônimo (anonymous). Até o fim do século XVII, a palavra anônimo (anonymous) significava "uma pessoa cujo nome não é dado, ou é desconhecido"7 (MASTEN, 1997, p. 12). É apenas depois dessa data que a definição moderna da palavra irá surgir, significando "sem o nome do autor; de autoria desconhecida ou não reconhecida"8 (MASTEN, 1997, p. 12), estabelecendo, então, conexão entre uma obra e seu autor. Por volta de 1676, portanto, a necessidade dessa associação entre autor e obra começa a se materializar. Como afirmado por Jeffrey Masten, "a emergência do autor é marcada pela percepção de sua ausência"9 (1997, p. 12). Dessa forma, enquanto Roland Barthes discute a "morte do autor", aqui estamos de certa forma tratando do "nascimento do autor" (MARSTEN, 1997) ao abordar um período e prática, com a produção teatral, em que a ideia de autoria como a concebemos atualmente não existia ainda. Como apontado por Michel Foucault acerca da visão atual da relação autor-texto:

os discursos "literários" não podem mais ser aceitos senão quando providos da função autor: a qualquer texto de poesia ou de ficção se perguntara de onde ele vem, quem o escreveu, em que data, em que circunstâncias ou a partir de que projeto. O sentido que lhe é dado, o status ou o valor que nele se reconhece dependem da maneira com que se responde a essas questões. E se, em consequência de um acidente ou de uma vontade explícita do autor, ele chega a nós no anonimato, a operação é imediatamente buscar o autor. O anonimato literário não é suportável para nós; só o aceitamos na qualidade de enigma. A função-autor hoje em dia atua fortemente nas obras literárias. (2009, p. 276)

Dessa forma, temos um contraponto interessante para a cultura de colaboração que viemos apresentando até aqui. Ben Jonson e William Shakespeare vão ser dramaturgos importantes para a discussão acerca do conceito de autoria neste artigo, pois parecem ter encontrado formas de exercer controle sobre as suas obras, como demonstraremos em seguida. Seja de forma intencional ou não, as situações de Jonson e Shakespeare se destacam do que acontecia com a maioria dos autores da época. Dessa forma, eles se mostram exemplares para entendermos mais sobre o conceito de autoria do período, além dos meios de controle de textos publicados e performáticos.

\section{BEN JONSON: COLABORAÇÃO E PUBLICAÇÃO}


Bem Jonson foi um dramaturgo muito renomado da modernidade nascente inglesa. Ele foi o primeiro poeta laureado da Inglaterra protestante, a primeira celebridade literária (BUTLER \& RICKARD, 2020) e muitas outras atribuições. Jonson, no entanto, é um dramaturgo muito pouco estudado fora do contexto britânico, embora tenha tido grande fama e obras renomadas. $\mathrm{O}$ autor produziu obras em diversos gêneros literários durante a sua carreira, dos epigramas às peças teatrais e suas famosas mascaradas ${ }^{10}$. Jonson foi um autor que sempre afirmou e reafirmou a sua autoridade sobre os seus textos. A sua própria posição como poeta laureado parece ter demandado ainda mais o estabelecimento dessa autoridade. De fato, essa vontade aparece desde o seu primeiro inquarto $^{11}$ publicado, com Every Man Out of His Humour em 1600, culminando na subsequente publicação de suas obras no Fólio de 1616.

Jonson é, portanto, uma figura excepcional para discutir a noção de autoria do início da Era Moderna inglesa, visto que se posiciona antagonicamente à cultura de colaboração disseminada na sociedade da época, parecendo estar mais próximo à noção moderna do conceito. De fato, como afirmado por George Chaplin, "o desenvolvimento de Jonson como autor, em outras palavras, não pode ser separado de suas contribuições para o desenvolvimento do próprio conceito de autoria"12 (2002, p. 57-58).

Jonson colaborou diversas vezes com outros dramaturgos durante a sua carreira. O autor, no entanto, não teve muita sorte com a maioria dessas parcerias, sendo acusado de traição com Sejanus His Fall (1603), preso e ameaçado de mutilação por Eastward Ho (1605), e outras. De fato, Eastward Ho foi a última peça colaborativa do dramaturgo. Bem Jonson, então, parece querer se desassociar da cultura de colaboração do teatro da época, como mencionado anteriormente, e isso se mostra presente na constante reafirmação da autoridade sobre os seus textos por meio de suas publicações, estabelecendo autoria e controle sobre as suas obras.

Esse controle estabelecido por Jonson em suas publicações é algo que ele começa a impor desde o início de sua carreira. Como afirmado por Stephen Orgel (1991), Jonson faz de tudo para controlar ao menos os seus textos publicados, "precisamente porque não tem autoridade suficiente nas versões teatrais. A única maneira de Jonson afirmar sua autoridade sobre o texto era alterá-lo e publicá-lo: a autoridade, isto é, está na publicação" ${ }^{13}$ (p. 84, grifo nosso). 
Ao passo que no âmbito teatral, com seus textos em performance, temos o controle das companhias de teatro, que se tornavam detentoras das peças depois de adquiri-las; no âmbito da publicação, os editores ocupavam posição análoga. Isso, no entanto, não foi o caso com Bem Jonson, que parece ter encontrado na publicação uma alternativa viável para reafirmar a sua autoridade.

É importante destacar, no entanto, que até mesmo a publicação era algo suscetível a instabilidade. Isso pode ser ilustrado pelo destaque dado ao nome do autor em suas obras impressas, e os frontispícios são interessantes de se notar para esse fim. De fato, a situação com a peça de Jonson The Case is Altered (1609) se destaca nesse quesito, visto que o texto teatral teve três frontispícios diferentes durante um único ano. A primeira versão destaca o nome de Bem Jonson, a segunda simplesmente apaga o nome dele e a terceira devolve o nome do autor à folha. Tal exemplo ilustra a instabilidade não só da forma com que as peças eram impressas naquele momento, mas também do tratamento dado aos dramaturgos no período.

Embora o maior símbolo de sua voz autoral seja o seu Fólio de 1616, Jonson já vinha mostrando essa vontade de controle da autoria de suas obras desde as suas primeiras publicações in-quarto, como iremos demonstrar. Como apontado por Eugene Giddens (2010), “Jonson é tradicionalmente visto como a dramaturgo renascentista mais interessado em sua própria reputação em publicação"14 (p. 65). Em Every Man Out of His Humour (1600), ele já se refere a si mesmo como autor, a primeira vez que o termo aparece se referindo a peças publicadas provenientes do teatro profissional inglês (BUTLER \& RICKARD, 2020). Como apontado por Martin Butler e Jane Rickard (2020): “Todos os seus in-quartos são cheios de prefácios, resumos, versos dedicatórios, [...], e utilizam notas marginais e layouts incomuns para promover a sua persona tipográfica, afastando o texto de seus primeiros públicos ou leitores e trazendo-o de volta para a mão modeladora do autor"15 (p. 8-9).

Esse aspecto também está bastante presente na publicação in-quarto de 1605 da peça Sejanus His Fall, que podemos caracterizar como a primeira vez em que Jonson buscou estabelecer a sua voz autorial de forma mais tangível. Sejanus foi uma peça que tinha sido primeiramente produzida em colaboração com outro dramaturgo, mas que Jonson faz questão de reescrever a parte colaborativa para a publicação. É a primeira peça teatral em que o dramaturgo irá escrever um texto endereçado diretamente ao seu leitor, 
com o seu To the Reader; além de ser também a primeira vez que Jonson irá acrescentar um argumento, aspecto clássico que faz um certo resumo da ação da obra. O frontispício da publicação também é digno de nota, visto que não menciona o nome da companhia de teatro que encenou a peça, como era de praxe no período, quando era mais comum a omissão do nome do autor em favor do nome da companhia (GIDDENS, 2010). A maior inovação nesta publicação, no entanto, é a presença de extenso aparato acadêmico, com notas explicativas acerca de fontes clássicas utilizadas pelo autor (GIDDENS, 2010). Dessa forma, como afirmado por Eugene Giddens (2010), "esse aparato editorial faz da peça mais um produto acadêmico que um trabalho colaborativo de teatro"16 (p. 66).

Volpone; or, the Fox (1605) também parece ilustrar um pouco da tensão do dramaturgo em relação à questão da autoria. Em meio ao cenário de colaboração estabelecido acima, o frontispício da peça se mostra destoante. Alguns aspectos a se destacar são: (i) o nome do dramaturgo em destaque pelo tamanho de sua fonte; (ii) o próprio título da peça com o pronome possessivo, indicando pertencimento ("BEM: IONSON/ his Volpone,"); e (iii) a ausência do nome da companhia de teatro que comprou o texto. O tema da colaboração aparece também no enredo da peça, com a dupla Mosca e Volpone, e, assim como aconteceu com muitas das colaborações de Bem Jonson na elaboração de textos teatrais, a parceria dos personagens também tem um fim inoportuno.

O Fólio de 1616, portanto, representa o ápice quando se trata do estabelecimento da autoria na carreira de Bem Jonson. Como apontado por Tiffany Stern (2004) acerca de fólios enquanto publicações: "um fólio era o maior tipo de livro que podia ser publicado. Para publicá-lo, folhas de papel eram dobradas apenas uma vez, e o resultado era um volume tão caro quanto imponente. O tamanho do fólio era comum para bíblias ou para as obras completas de autores clássicos renomados"17 (p. 47). Ao publicar as suas obras nesse formato, Bem Jonson posiciona a si mesmo e as suas obras como clássicas. Além disso, Jonson faz uso da palavra works (obras) no título da publicação - The Works of Benjamin Jonson -, uma palavra que normalmente não era utilizada para se referir a peças teatrais, um gênero textual visto como não dignificado naquele momento, uma vez que peças eram encenadas em locais de pouca reputação, ao lado de estabelecimentos onde havia bear-baitings ${ }^{18}$, por exemplo.

No Fólio, ao deliberadamente selecionar apenas peças de sua autoria individual, excluindo e/ou reescrevendo peças colaborativas, além de revisar o texto da publicação 
em geral, Bem Jonson atua como o seu próprio editor, estabelecendo controle sobre suas obras e o que ele gostaria de deixar como legado (BUTLER \& RICKARD, 2020). Como apontado por Eugene Giddens (2010), “o envolvimento de Jonson na produção do fólio foi intenso, embora ele pareça ter tido mais zelo por certas partes do que outras"19 (p. 67). Um dos maiores exemplos de mudanças feitas em peças para a publicação em Fólio está presente na peça Every Man In His Humour em que Jonson transpôs a sua peça, que inicialmente se passava na Itália, para a Inglaterra elisabetana. Sejanus, curiosamente, perde as suas notas explicativas em sua versão do Fólio.

Como explicitamos nesta seção, Bem Jonson foi um autor que afirmou e reafirmou autoria e controle sobre os seus textos constantemente ao longo de sua carreira. Essa característica já se mostra presente desde a sua primeira publicação, em 1600, culminando no maior símbolo desse percurso com o seu Fólio, do qual Jonson pode ser creditado como editor, além de autor. O Fólio, portanto, é o cume de seus esforços no estabelecimento de sua voz autorial como algo indiscutível, em meio a um contexto em que autores, de forma geral, estavam longe de ser a autoridade máxima sobre os textos que produziam.

\title{
SHAKESPEARE: A EXCEÇÃO?
}

A situação se mostra bem diferente quando se trata de William Shakespeare, que demonstra uma outra realidade do período. Ao contrário do caso de Jonson, o Fólio shakespeariano só foi ser publicado postumamente, em 1623. Como apontado por David Scott Kastan (2001):

\begin{abstract}
Claramente, o comprometimento do próprio Shakespeare com a publicação estava reservado para a sua poesia narrativa. [...] As suas peças publicadas, no entanto, não mostram sinal algum do envolvimento de Shakespeare. Ele as escreveu para o teatro e não para o público leitor; elas eram scripts para serem encenados, não peças para serem lidas. ${ }^{20}$ (p. 6, grifo nosso)
\end{abstract}

Podemos dizer de forma geral, portanto, que Shakespeare não parece ter se preocupado com a publicação de suas peças durante a sua carreira. Apenas dezoito peças do dramaturgo foram publicadas em vida, e nenhuma dessas edições é uma versão declaradamente autorizada por ele (KASTAN, 2001). As publicações de suas peças 
foram, no entanto, muito populares no período, e o número total delas ultrapassou o de qualquer outro dramaturgo daquela época. Shakespeare, no entanto, parece ter encontrado, possivelmente de forma não deliberada, outra maneira de exercer controle sobre as suas obras. Como afirmado por David Scott Kastan (2001):

\begin{abstract}
A aparente indiferença de Shakespeare à publicação de suas peças, a sua manifesta falta de interesse em reafirmar a sua autoridade sobre elas, sugere o quão pouco ele investiu nas noções de autoria individualizada que, ironicamente, o seu nome veio a representar tão triunfantemente. Literalmente, o seu investimento estava em outro lugar: na lucrativa parceria da companhia de teatro. Ele trabalhou confortavelmente dentro de suas colaborações necessárias e claramente não sentiu necessidade de reivindicar os textos de suas peças como seus quando eles começaram a circular enquanto publicações e a serem $\operatorname{lidos}^{21}$ (p. 16)
\end{abstract}

Além de ser ator e dramaturgo, Shakespeare também era acionista da companhia de teatro Chamberlain's Men (depois chamada de King's Men), para a qual produziu peças durante toda a sua carreira. Além disso, Shakespeare também se destaca da cultura colaborativa quando se trata da própria composição de peças, visto que a maioria delas são de autoria individual, com a produção da maior parte de suas colaborações no fim de sua carreira.

Não se sabe de que forma as peças de Shakespeare produzidas antes 1594 chegaram às mãos da Chamberlain's Men, mas de fato chegaram e, depois desse ano, o dramaturgo se tornou o poeta residente da companhia. Sendo assim, após essa data, e, portanto, desde o início de sua carreira, Shakespeare vendeu todas as suas peças para a sua própria companhia de teatro, situação bem diferente da de Ben Jonson, que teve as suas peças adquiridas por diversas companhias ao longo de sua carreira.

Sendo Shakespeare, então, um dos acionistas da companhia e também ator, o controle estabelecido por ele parece ocorrer por conta de sua participação em diversas instâncias de colaboração do teatro, graças às diferentes funções que desempenhava, desde a concepção de uma peça até a sua encenação. Como apontado por Stephen Orgel (1991), "Shakespeare pode ser distinguido da maioria dos outros dramaturgos apenas porque participou de mais partes da colaboração"22 (p. 87). Dessa forma, viemos situando Shakespeare como alguém que trabalhou em um meio necessariamente colaborativo, onde ele atuava como acionista da companhia de teatro, ator, dramaturgo, dentre outros papéis que ele possa ter assumido. Como apontado por Will Sharpe (2014): 
Ele era o principal escritor da companhia, embora suas responsabilidades também incluíssem atuar, trabalhar com outros acionistas e atores em seus textos e de outros no que poderíamos chamar de ensaios, sem mencionar as responsabilidades administrativas envolvidas na gestão de um negócio. Portanto, podemos ampliar o nosso senso do que a colaboração shakespeariana envolve além da composição conjunta de uma peça. ${ }^{23}$ (p. 32)

Shakespeare, portanto, é um autor excepcional para discussão acerca da noção de autoria da modernidade nascente inglesa, justamente por conta de seu contexto com as diversas posições que ocupava na cultura colaborativa do teatro renascentista. A sua subsequente recepção como um autor que parece se destacar dessa cultura de colaboração se mostra errônea e descolada da realidade do âmbito teatral das eras elisabetana e jacobina como um todo. Dessa forma, trouxemos uma outra faceta de Shakespeare neste artigo, como um homem do teatro do início da Era Moderna inglesa.

\section{CONSIDERAÇÕES FINAIS}

O presente artigo buscou discutir a noção de autoria difundida na produção teatral da modernidade nascente inglesa. Textos teatrais são em si colaborativos, e isso é especialmente interessante de se notar em peças das eras elisabetana e jacobina, visto que há uma predominância de textos colaborativos nesse período. Vimos como Ben Jonson e William Shakespeare, dramaturgos muito importantes da época, são figuras excepcionais para tratar desse conceito, visto que exerceram controle sobre as suas obras de formas diferentes; o primeiro de forma deliberada e o segundo aparentemente como consequência do nível de envolvimento no contexto em que ele estava inserido.

Dessa forma, o artigo se distancia da visão de Shakespeare que foca na predominância de peças de autoria individual durante a sua carreira e ressalta a sua posição como homem do teatro elisabetano e jacobino. Ben Jonson, um autor importantíssimo da modernidade nascente inglesa, tem escassa presença no Brasil, portanto, a consideração de suas obras e carreira se mostra relevante, principalmente sobre esse tema, que apareceu de forma proeminente diversas vezes em sua escrita.

\section{Referências}


BUTLER, Martin \& RICKARD, Jane (eds.). Ben Jonson and Posterity: Reception, Reputation, Legacy. Cambridge: Cambridge University Press, 2020.

CHAPLIN, Gregory. "Divided Amongst Themselves": Collaboration and Anxiety in Jonson's Volpone. ELH, v. 69, n. 1, 2002. p. 57-81.

FEATHER, John. "From rights in copies to copyright: The recognition of authors' rights in English law and practice in the sixteenth and seventeenth centuries". In: WOODMANSEE, Marta \& JASZI, Peter (Eds.). The Construction of Authorship. Durham: Duke University Press, 1999, p. 191-210.

FOUCAULT, Michel. Ditos e escritos (vol. III) - Estética: literatura e pintura, música e cinema. Trad. de Inês Autran Dourado Barbosa. Rio de Janeiro: Forense Universitária, 2009.

GIDDENS, Eugene. "Editions and Editors". In: SANDERS, Julie (eds.). Ben Jonson in Context. Cambridge: Cambridge University Press, 2010, p. 65-72.

KASTAN, David Scott. "Introduction". In: ; STALLYBRASS, Peter. (Eds.). Staging the Renaissance: reinterpretations of Elizabethan and Jacobean drama. New York: Routledge, 1991, p. 1-14.

Shakespeare and the book. Cambridge: Cambridge University Press, 2001.

MASTEN, Jeffrey A. Beaumont and/or Fletcher: collaboration and the interpretation of Renaissance drama. ELH, v. 59, n. 2, 1992. p. 337-356.

Textual intercourse: Collaboration, authorship, and sexualities in Renaissance drama. Cambridge: Cambridge University Press, 1997.

ORGEL, Stephen. "What is a text?". In: KASTAN, David Scott and STALLYBRASS, Peter (eds.). Staging the Renaissance: reinterpretations of Elizabethan and Jacobean drama. New York: Routledge, 1991, p. 83-87.

SHARPE, Will. Framing Shakespeare's Collaborative Authorship. In: Shakespeare Survey, Vol. 67: Shakespeare's Collaborative Work, v. 67, 2014. p. 29-43.

STERN, Tiffany. Making Shakespeare: From Stage to Page. Londres: Routledge, 2004.

Recebido em: 03/06/2021

Aceito em: 06/07/2021

\footnotetext{
1 "as many as half...incorporated the writing of more than one man."

2 “A tradução desta citação, assim como as demais nas quais não houver indicação do tradutor, são de minha autoria. No original: "the authority of a text derives from the author is almost never true."
} 
${ }^{3}$ A Stationer's Company era uma guilda que regulava os profissionais envolvidos na indústria editorial durante os séculos XVI e XVII, desde a impressão dos livros até a sua venda.

4 "collaborative play-texts disperse the authorial voice (or rather, our historically subsequent notion of the authorial voice)."

5 "the creation of a play was a collaborative process, with the author by no means at the center of the collaboration. The company commissioned the play, usually stipulated the subject, often provided the plot, often parcelled it out, scene by scene, to several playwrights. The text thus produced was a working model, which the company then revised as seemed appropriate. The author had little or no say in these revisions: the text belonged to the company, and the authority represented by the text- I am talking about the performing text—is that of the company, the owners, not that of the playwright, the author."

${ }^{6} \mathrm{O}$ documento diz que Henslowe pagou dez pounds a Jonson "for new adicyons for Ieronymo".

7 "A person whose name is not given, or is unknown"

8 "bearing no author's name; of unknown or unavowed authorship"

9 "The author's emergence is marked by the notice of its absence."

${ }^{10}$ As mascaradas (masques) consistiam em entretenimentos produzidos para apresentações diante da corte, gênero que se desenvolveu nos séculos XVI e XVII na Europa. Eles eram uma mistura de dança, teatro, música e grandes e opulentos cenários. Ben Jonson foi um dos principais autores desse tipo de entretenimento na Inglaterra, colaborando diversas vezes com o arquiteto Inigo Jones (1573-1652) durante os reinados de Jaime I (1603-1625) e Carlos I (1625-1649).

${ }^{11}$ As publicações conhecidas como "in-quartos" eram constituídas por folhas divididas pela metade duas vezes, formando quatro páginas dobradas ou oito páginas cada folha. Elas eram publicações mais baratas, feitas com papel de menor qualidade e, portanto, facilmente descartadas.

12 "Jonson's development as an author, in other words, cannot be divorced from his contributions to the development of the concept of authorship itself."

13 "Precisely because he hasn't sufficient authority in the theatrical versions. The only way for Jonson to assert his authority over the text was to alter it and publish it: the authority, that is, lies in the publication."

14 "Jonson is traditionally seen as the Renaissance dramatist most interested in his own print reputation."

15 "All of his quartos bristle with prefaces, summaries, dedicatory verses [...], and use marginalia and unusual layouts to promote his typographical persona, drawing the text away from their first audiences or readers and back into the author's shaping hand."

16 "This editorial apparatus makes the play more a product of scholarship than a collaborative work of theatre."

17 "A folio was the largest kind of book that could be printed. To print it, sheets of paper were folded only once, and a result was a tome as expensive as it was imposing. The folio size was usual for bibles or the complete works of reputed classical writers."

${ }^{18}$ Bear-baiting era um tipo de entretenimento em que ursos eram acorrentados a postes e então atacados por cães. As pessoas iam assistir e apostar no esporte. A prática foi proibida em 1835. Mais informações disponíveis em: https://www.history.com/news/the-gruesome-blood-sports-of-shakespearean-england. Último acesso em: 26 MAI 2021.

19 "Jonson's involvement in the production of the folio was heavy, though he seems to have taken more care over certain parts than others." 
20 “Clearly, Shakespeare's own commitment to print was reserved for his narrative poetry. [...] The published plays, however, show no sign of Shakespeare's involvement. He wrote them for the theater and not for a reading public; they were scripts to be acted not plays to be read."

21 "Shakespeare's apparent indifference to the publication of his plays, his manifest lack of interest in reasserting his authority over them, suggests how little he had invested in the notions of individuated authorship that, ironically, his name has come so triumphantly to represent. Literally his investment was elsewhere: in the lucrative partnership of the acting company. He worked comfortably within its necessary collaborations, and clearly felt no need to claim his play texts as his own as they began to circulate in print and be read."

22 "Shakespeare can be distinguished from most other playwrights only because he was in on more parts of the collaboration."

23 "He was the company's principal writer, though his responsibilities also included acting, working with fellow sharers and actors on his and others' texts in what we might call rehearsals, not to mention the administrative responsibilities involved in the running of a business. So we might widen our sense of what Shakespearian collaboration involves beyond the joint composition of a play." 